\title{
Extensive Coronary Thrombosis in a COVID-19 Patient
}

\author{
Madoka Sano, Kitae Kim and Yutaka Furukawa
}

Key words: COVID-19, STEMI

(Intern Med Advance Publication)

(DOI: 10.2169/internalmedicine.8826-21)
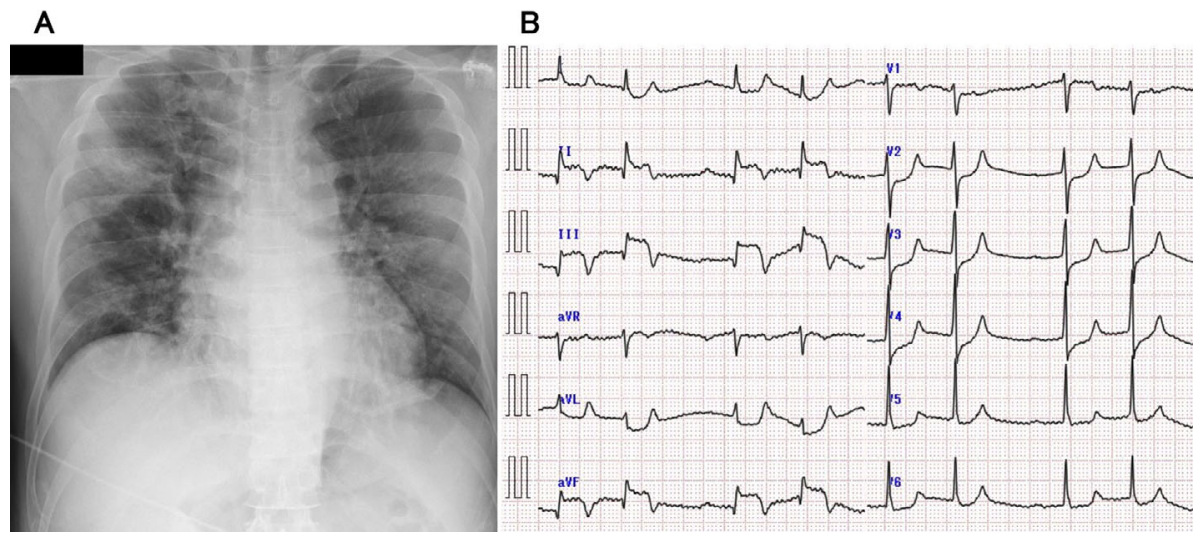

Picture 1.
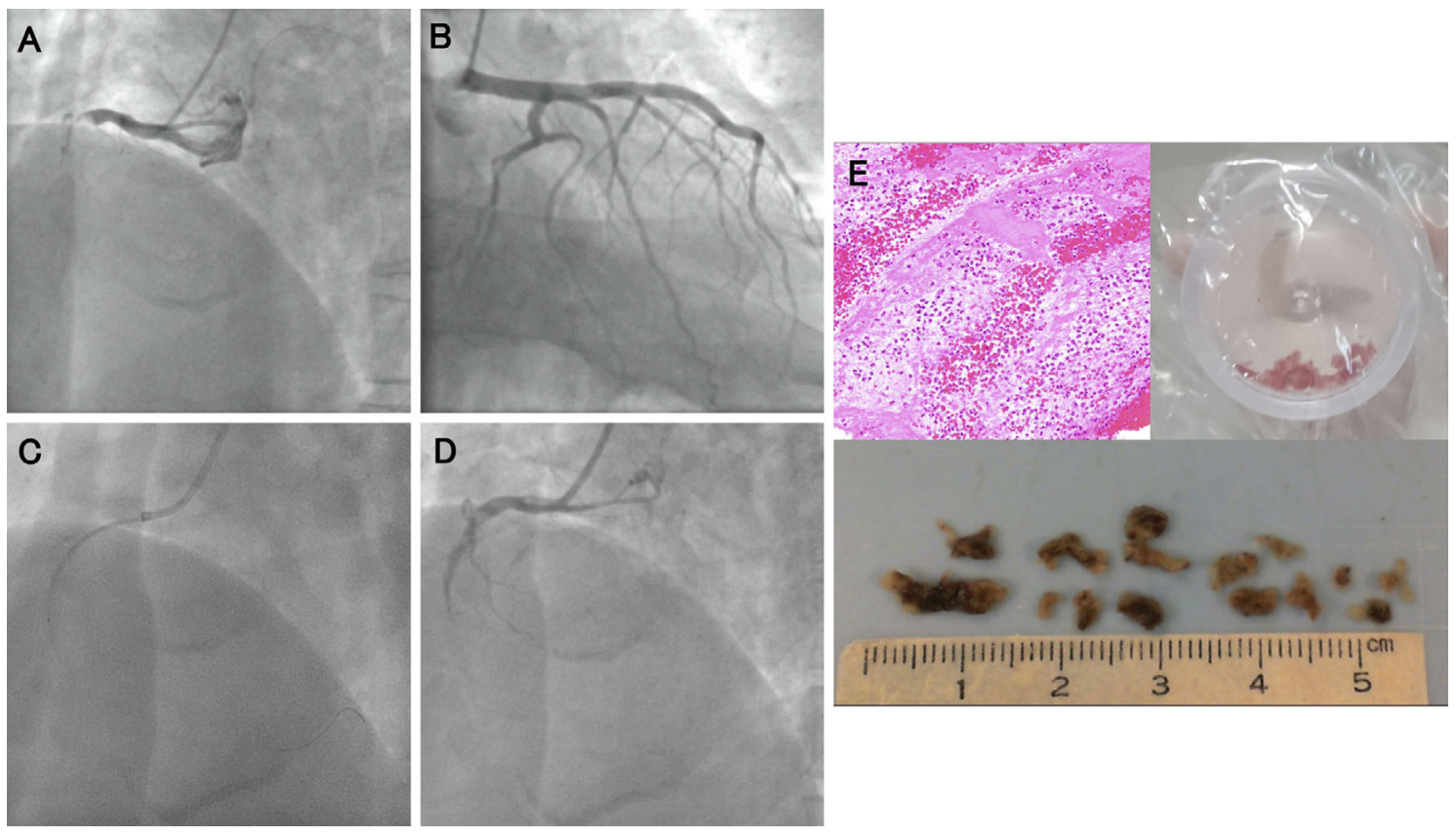

Picture 2.

Department of Cardiovascular Medicine, Kobe City Medical Center General Hospital, Japan

Received: October 12, 2021; Accepted: November 17, 2021; Advance Publication by J-STAGE: December 28, 2021

Correspondence to Dr. Kitae Kim, kitae.kim0329@gmail.com 

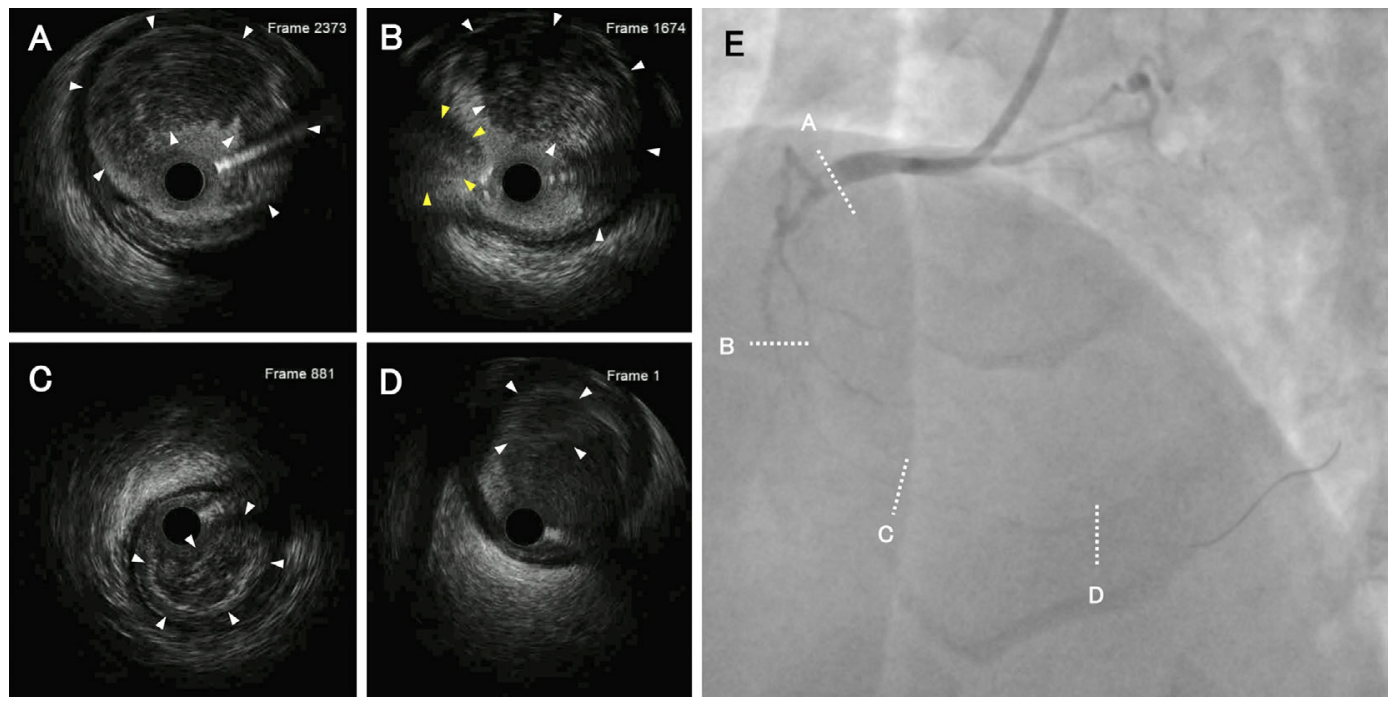

Picture 3.
A 68-year-old man presented with a 7-day history of malaise and 2-day history of worsening chest discomfort. He had had close contact with a person infected with SARSCoV-2 12 days before admission. On arrival, he was afebrile, hypotensive and hypoxic. Chest X-ray revealed bilateral pulmonary infiltrates. An electrocardiogram showed sinus rhythm with premature atrial contractions, inferior STsegment elevations and reciprocal changes in the anterolateral leads Picture 1. A laboratory analysis revealed elevated levels of troponin I (121.94 ng/mL), D-dimer $(8.46$ $\mu \mathrm{g} / \mathrm{mL})$, C-reactive protein $(11.48 \mathrm{mg} / \mathrm{dL})$, blood urea nitrogen $(119.7 \mathrm{mg} / \mathrm{dL})$, and creatinine $(4.65 \mathrm{mg} / \mathrm{dL})$. Coronary angiography demonstrated proximal right coronary artery (RCA) occlusion. Aspiration thrombectomy was repeated, and multiple thrombi were removed; however, the distal coronary flow could not be restored Picture 2. Intravascular ultrasound demonstrated hypo-echoic, heterogenous, welldelineated lesions that were consistent with extensive thrombus filling the entire RCA without clear findings of plaque rupture Picture 3. Histologically the thrombi were composed of fibrin and neutrophilic infiltrates, and no fragments of atherosclerotic plaque were present. After the procedure, a nasopharyngeal swab for SARS-CoV2 reverse polymerase chain reaction (PCR) showed a positive result, indicating that the leading etiology of his hypoxia was COVID-19 pneumonia. COVID-19 causes coagulation abnormalities, in- cluding activation of platelets and the coagulation cascade (1), as well as endothelial cell injury (2). ST-elevation myocardial infarction (STEMI) in patients with concurrent COVID-19 was associated with an increased thrombus burden (3). In the present case, extensive coronary artery thrombosis rather than plaque rupture, caused by a hypercoagulable state and endothelial injury due to COVID-19 infection, may have been responsible for STEMI.

The authors state that they have no Conflict of Interest (COI).

\section{References}

1. Masi P, Hékimian G, Lejeune M, et al. Systemic Inflammatory Response Syndrome Is a Major Contributor to COVID-19Associated Coagulopathy: Insights From a Prospective, SingleCenter Cohort Study. Circulation 142: 611-614, 2020.

2. Varga Z, Flammer AJ, Steiger P, et al. Endothelial cell infection and endotheliitis in COVID-19. Lancet 395: 1417-1418, 2020.

3. Choudry FA, Hamshere SM, Rathod KS, et al. High Thrombus Burden in Patients With COVID-19 Presenting With ST-Segment Elevation Myocardial Infarction. J Am Coll Cardiol 76: 11681176, 2020.

The Internal Medicine is an Open Access journal distributed under the Creative Commons Attribution-NonCommercial-NoDerivatives 4.0 International License. To view the details of this license, please visit (https://creativecommons.org/licenses/ by-nc-nd/4.0/).

\section{(C) The Japanese Society of Internal Medicine} Intern Med Advance Publication 